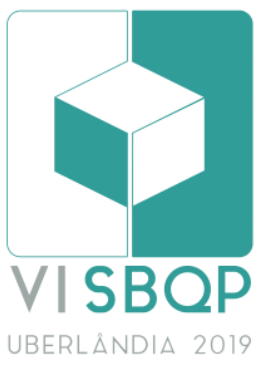

\title{
ESTRATÉGIA PARA ANÁLISE DE EDIFÍCIOS RESIDENCIAIS VISANDO A QUALIDADE
}

\author{
DIAS, Ricardo da Silva \\ Universidade Estadual de Londrina, e-mail: ricardodiasconta@gmail.com \\ GUADANHIM, Sidnei Junior \\ Universidade Estadual de Londrina, e-mail: sjg@vel.br
}

\begin{abstract}
RESUMO
Este artigo resulta de pesquisa em desenvolvimento sobre como melhorar edifícios residenciais no Brasil. Espera-se enfrentar a monotonia e prejuízos decorrentes da repetição da planta em "H" verificando a viabilidade de outros desenhos a partir de casos europeus. Portanto, o objetivo deste artigo é propor uma estratégia metodológica para a análise sistemática de edifícios de modo a possibilitar comparações entre casos brasileiros e europeus, visando identificar alternativas de plantas do edifício compatíveis com o contexto nacional. A partir de revisão bibliográfica e estudo de caso a análise se constituiu por três etapas: 1. Seleção de casos através de indicadores e parâmetros de qualidade, 2. Caracterização e comparação dos casos e 3. Verificação da aplicabilidade das plantas utilizando, para isso, a legislação urbana de Londrina, PR. A sua aplicação revelou que é possível comparar edifícios em contextos tão distintos, que a legislação permite variações nas plantas semelhantes aos casos europeus e que estes podem indicar alternativas para melhorar a qualidade de novos edifícios no Brasil.
\end{abstract}

Palavras-chave: Edifício residencial, Estratégias projetuais, Densidade habitacional.

\begin{abstract}
This article results from research in development on how to improve residential buildings in Brazil. It is hoped to face the monotony and damages resulting from the repetition of the plant in "H" verifying the viability of other drawings from European cases. Therefore, the objective of this article is to propose a methodological strategy for the systematic analysis of buildings in order to allow comparisons between Brazilian and European cases, in order to identify alternatives of building plans compatible with the national context. From a bibliographic review and case study the analysis consisted of three stages: 1. Selection of cases through indicators and quality parameters, 2. Characterization and comparison of cases and 3. Verification of the applicability of the plans using, for this, the urban legislation of Londrina, PR. Its application has shown that it is possible to compare buildings in such different contexts, that the legislation allows variations in plants similar to European cases and that these can indicate alternatives to improve the quality of new buildings in Brazil.
\end{abstract}

Keywords: Collective Housing, Design strategies, Housing density.

DIAS, R. S.; GUADANHIM, S. J. Estratégia para análise de edifícios residenciais visando a qualidade. In: SIMPÓSIO BRASILEIRO DE QUALIDADE DO PROJETO NO AMBIENTE CONSTRUÍDO, 6., 2019, Uberlândia. Anais... Uberlândia: PPGAU/FAUeD/UFU, 2019. p. 306-319. DOI https://doi.org/10.14393/sbqp19030. 


\section{INTRODUÇÃO}

Os edifícios residenciais verticais no Brasil tornaram-se opções viáveis de moradia a distintas classes sociais durante a década de 1990 (VILLA et al., 2018). Esta modalidade de habitação tornou-se a realidade de um número crescente de pessoas e famílias, com diferentes perfis, que vislumbram segurança, praticidade, economia (PINHO, 2005) ou status social (VILLA, 2008). O mercado imobiliário, como resposta a demanda, passou a apresentar, em grande parte, excessiva padronização dos projetos arquitetônicos e das unidades habitacionais (VILLA, 2008). Independente dos distintos cenários ambientais, sociais e culturais, os mesmos projetos são reproduzidos indiscriminadamente (VILLA et al., 2018). Segundo Camargo (2017) a monotonia em bairros recentes brasileiros se propaga através da repetição da planta do edifício em "H" com poucas variações. Os resultados são edifícios com baixas taxas de ocupação, altos coeficientes de aproveitamento, extensos recuos e torres no centro do lote que desencorajam comércios em áreas onde é permitido O uso misto, restringindo o tanto o uso como o público (CARVALHO, 2008).

Os impactos negativos decorrentes a aglomeração deste padrão são inegáveis. Valores como segurança, homogeneidade social e lazer exclusivo são cada vez mais representados por muros, cercas, guaritas fortificadas e estão alterando expressivamente a qualidade dos espaços públicos no Brasil (CALDEIRA, 2000). Nesse sentido Mauá (2015) evidencia o impacto dos extensos muros no uso satisfatório da rua e Vivian e Saboya (2012) relacionam grandes áreas muradas e pouca permeabilidade visual e de acessos ao aumento dos índices de criminalidade. Com relação à verticalização Silveira; Silveira (2014) indicam que a aglomeração desta pode alterar a insolação e direcionamento dos ventos, além de congestionamentos, polvição do ar, carências de áreas verdes, lazer público e relações de vizinhança.

Diante desse cenário brasileiro, percebe-se a necessidade de identificar alternativas de plantas do edifício, compatíveis com o contexto nacional, de modo a encorajar a experimentação e diversidade pelos empreendedores e arquitetos para elevar a qualidade do conjunto. A planta do edifício, neste trabalho, refere-se à configuração geométrica resultante da organização dos apartamentos e das circulações comuns verticais e horizontais. Entende-se que a planta é a base da volumetria (CHING, 1997), portanto, variações na base refletirão em todo o edifício.

Há evidências que edifícios estrangeiros, principalmente os europeus, podem contribuir na identificação destas alternativas. Guadanhim (2014) levantou e estudou 27 edifícios residenciais cuja maioria encontra-se na Europa e apresentam características que superam o atendimento da demanda. Em muitos casos estes edifícios apresentam grandes diferenças com relação aos edifícios brasileiros no que se refere ao número de dormitórios, de apartamentos e suas áreas. Entretanto, Kanashiro (2014) destaca que os aspectos normativos deste grupo extrapolam para níveis qualitativos que direcionam a paisagem e 
enfatiza a relação positiva destes edifícios com as áreas públicas. Notase que a preocupação não está restrita apenas aos aspectos econômicos do empreendimento e abrange a coletividade.

No Brasil os fatores econômicos são determinantes na concepção dos empreendimentos (PINHO, 2005). Trata-se de uma realidade inerente à situação econômica e precisa ser considerada ao tentar extrair alternativas a partir de casos estrangeiros. Obviamente o perfil econômico, social e cultural europeu também possui significativos contrastes com o brasileiro, porém, Benevolo (2006) coloca que a metodologia europeia continua sendo "uma contribuição aplicável em qualquer lugar, um corretivo, aliás, para conseguir que grandes transformações quantitativas sejam acompanhadas em todo lugar de um devido cuidado qualitativo".

Neste sentido o presente trabalho, fragmento de pesquisa maior, objetiva apresentar uma estratégia de análise de edifícios residenciais, brasileiros e europeus. Esta análise representa a primeira etapa do processo de identificação de alternativas de planta de edifício. Por isso, as alternativas preliminares resultantes desta etapa serão identificadas visando aumentar a sua aceitação pelas incorporadoras e pelos consumidores. Além disso, espera-se que estas alternativas apresentem aspectos básicos para agregar qualidade aos espaços públicos como a rua e que sejam viáveis segundo a legislação urbana. Para tanto, a compreensão dos aspectos fundamentais para as incorporadoras ao conceber um novo empreendimento e para os usuários ao buscar por um imóvel é essencial. Da mesma forma o conhecimento de recomendações para aumentar a qualidade de ruas e de maneiras de verificar o potencial dos índices urbanísticos existentes de modo a verificar a viabilidade de outros desenhos de plantas. A revisão bibliográfica possibilitou a compreensão e o conhecimento destes aspectos.

\section{REVISÃO BIBLIOGRÁFICA}

A seleção do terreno, concepção financeira e a formulação do programa de necessidades compõem a etapa inicial do desenvolvimento de novos empreendimentos residenciais no Brasil (RODRIGUEZ E HEI NECK, 2007). Segundo Campos Filho (2001) o valor da terra é determinante na formatação da planta do edifício, por isso, o aumento crescente do número de pavimentos e de apartamentos. Um dos principais objetivos é a diluição do custo do lote, aproveitando ao máximo o coeficiente de aproveitamento (CARVALHO, 2008). Com relação aos consumidores ou usuários as principais preocupações durante a compra de um apartamento referem-se à área privativa e número de dormitórios (GONZAGA, 2003; BRANDSTETTER, PACHECO, CANEDO 2012; SILVA, 2013). Estes autores indicam outras preocupações como preço, ventilação, localização, vagas de garagem, unidades de apartamento por pavimento, segurança, flexibilidade, etc., porém, a área privativa e o número de dormitórios são comuns em seus estudos. 
Assim, foi possível determinar quatro indicadores diretamente relacionados com o contexto imobiliário brasileiro: 1. Número de apartamentos ou densidade habitacional, 2. Área do lote, 3. Área do apartamento e 4. Número de dormitórios.

A literatura e levantamentos revelaram parâmetros numéricos para referenciar estes indicadores. A área dos apartamentos e número de dormitórios foram extraídos da revisão bibliográfica e apresentam entre 50 e $120 \mathrm{~m}^{2}$ e entre dois e quatro dormitórios (BRANDÃO, 2002; VILLA, 2008; ORSTEN, VILLA, ONO, 2010; TEIXEIRA et. al., 2015; CAMARGO, 2017; EMBRAESP, 2019). Já os parâmetros com relação à densidade habitacional e área dos lotes foram extraídos de levantamento realizado em 23 edifícios residenciais verticais em construção no ano de 2018 em diferentes regiões do Brasil. Estes edifícios foram levantados a partir dos websites de 25 grandes incorporadoras e construtoras, segundo ranking anual da empresa Informações técnicas da construção (ITC) em 2017. Os lotes apresentam variações entre 0,1 a 2,5 hectares e a densidade habitacional entre 120 a 850 hab/ha.

Esses edifícios não resultam de método tipológico (CAMARGO, 2017). O que ocorre é mimetismo e reprodução de soluções assimiladas pelos usuários que desencorajam a busca por outras configurações. De acordo com Rocco (2006) os corretores resistem às inovações temendo prejuízos nas vendas. Isto influencia fortemente as incorporadoras a replicarem o modelo atual (QUEIRÓZ; TRAMONTANO, 2010).

De maneira contrastante, edifícios residenciais construídos em países mais desenvolvidos possuem nítidas características projetuais positivas que extrapolam 0 empreendimento. Recomendações feitas pela literatura para aumentar a qualidade da rua, intimamente relacionados com o projeto dos edifícios, podem ser facilmente identificadas em empreendimentos europeus. Mauá (2015) destaca as recomendações de Jacobs (1961), Gehl (1971), Rapoport (1978) Whyte (1980) Appleyard (1981) Bentley et al. (1999) e Carmona et al. (2010) como: variedade de usos, boa iluminação e ventilação (permeabilidade entre as volumetrias), riqueza visual, proximidade de espaços públicos, multiplicidade de caminhos, densidade de pessoas nas ruas, fachadas ativas, locais de estar, vegetação na calçada, trabalho e recreação próximos, acessibilidade e mobilidade, variedade de usuários, visibilidade, calçadas espaçosas, diversidade comercial, variedade de tipos de edifícios, correlação entre espaços internos e externos, fechamentos (muros) permeáveis, distâncias confortáveis para andar, fácil acesso às entradas e não murar as esquinas.

A maioria destas recomendações para aumentar a qualidade de rua, é viabilizada ou potencializada através das características da planta do edifício e dos índices estabelecidos pela legislação urbana. Carvalho (2008) discorre sobre o caso de São Paulo, capital, onde a legislação induzia a diminuição da taxa de ocupação e provocou consequências como o aumento excessivo da altura dos edifícios, recuos restritivos que deslocam o edifício para o núcleo do lote, área do pavimento térreo 
restrita à projeção e inibição do uso misto.

O gráfico spacemate desenvolvido por Berghauser Pont e Haupt (2009) relaciona índices urbanísticos como taxa de ocupação, coeficiente de aproveitamento, número de pavimentos e permite prever os resultados a partir de variações destes. Portanto, este gráfico se apresenta como uma ferramenta para verificar induções ou restrições da legislação e avaliar a viabilidade de outros desenhos de plantas.

Para tanto é necessária a caracterização dos casos considerando os dados para subsidiar a montagem do gráfico spacemate. A literatura revisada também indicou alguns dados para comporem esta caracterização como: volumetria, número de blocos, uso misto e número de apartamentos por pavimento. Guadanhim (2014) sugere a classificação do tipo de organização das unidades, tipo de circulação e tipo da planta de modo a encontrar a essência tipológica. A área do pavimento tipo, área de circulação por pavimento, área total de circulação e a área total construída também foram consideradas.

As áreas de lazer coberto e descoberto também se apresentaram como dados relevantes para comparações. O conceito de condomínio-clube com extensas áreas e inúmeras atividades está presente na maioria dos empreendimentos brasileiros mesmo não sendo uma prioridade para os usuários na hora da compra (VILLA, 2008) talvez um diferencial. Entretanto, estas áreas se concebidas a partir de relações com espaços públicos podem agregar qualidade ao conjunto. O índice de compacidade e comprimento do perímetro da planta apresentam relação direta com os custos do empreendimento (MASCARÓ, 2010) e também serão comparados.

A fundamentação desempenha papel determinante neste trabalho, pois, oferece o suporte necessário para a proposição da estratégia de análise.

\section{MÉTODO}

A partir do objetivo foi possível classificar esta pesquisa como exploratória por buscar maior familiaridade com o problema para construir hipóteses e aprimorar ideias. Estas pesquisas assumem a forma de pesquisa bibliográfica ou estudo de caso (GIL, 2002). Segundo Yin (2003) questões do tipo "como" sobre um conjunto contemporâneo de acontecimentos cujo pesquisador tem pouco ou nenhum controle favorecem o método de estudo de caso. De acordo com Gil (2002) este método visa explorar situações reais com limites pouco definidos, descrever a situação do contexto, formular hipóteses, explicar variáveis causais do fenômeno e preservar o caráter unitário do objeto.

Portanto, a estratégia de pesquisa adotada foi o estudo de caso para aplicar e avaliar a estratégia de análise proposta. Os procedimentos metodológicos foram: revisão de literatura para identificar indicadores e parâmetros, recomendações de qualidade da rua e maneiras de relacionar índices urbanísticos, proposição da estratégia, aplicação em 
casos e avaliação. A figura 1 ilustra a ordem dos procedimentos metodológicos.

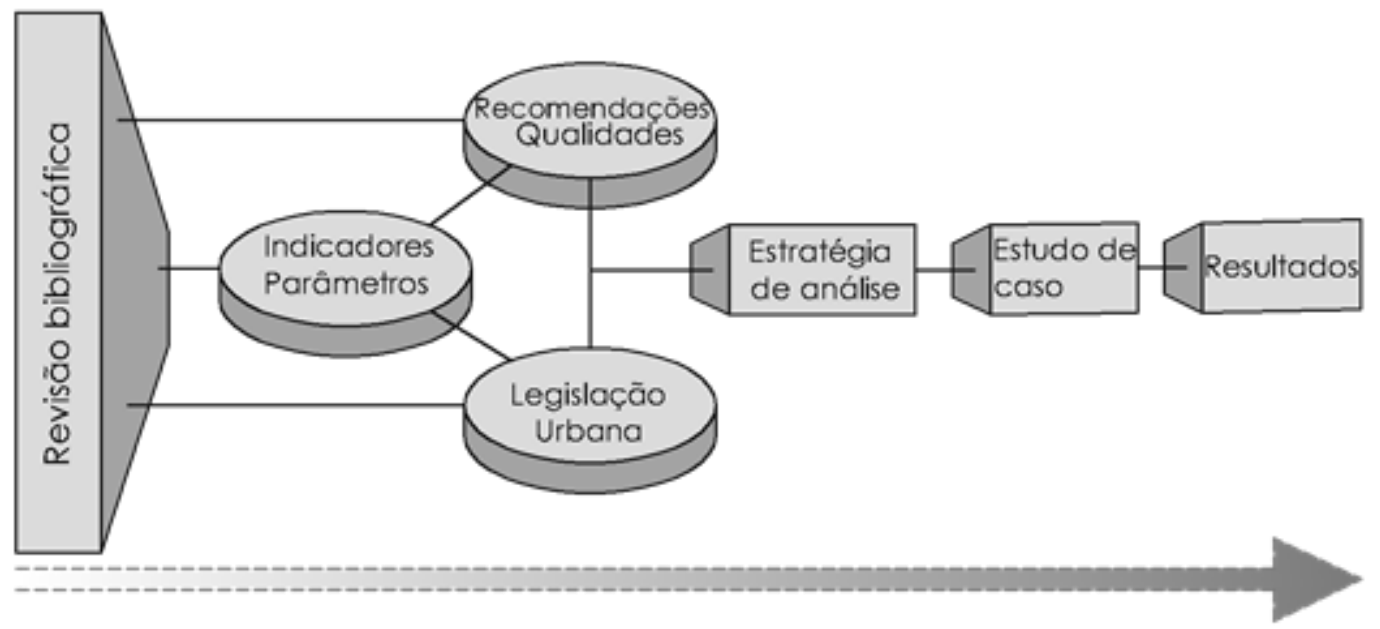

Figura 1 - Procedimentos metodológicos

Fonte: o autor (2019)

\section{RESULTADOS E DISCUSSÃO}

\subsection{Estratégia de análise de edifícios residenciais}

Três etapas compõem a estratégia de análise proposta e estão apresentadas no quadro 1 . Os casos selecionados devem se enquadrar nos parâmetros dos indicadores com mínimas variações. A identificação das recomendações de qualidade deve ocorrer através de reconhecimento visual feito pelo pesquisador. Em casos mais subjetivos como iluminação e ventilação o critério de reconhecimento será a presença de permeabilidade ou distanciamento entre os blocos sugerido por Carmona et al. (2003). A caracterização e comparação devem envolver levantamento ou produção de material gráfico para extrair os dados estabelecidos. Já a análise da legislação urbana deverá ocorrer através da justaposição dos casos no gráfico spacemate de modo a verificar se os índices urbanísticos permitem a implantação das alternativas de plantas extraídas dos casos internacionais. 
Quadro 1 - Estratégias de análise

\begin{tabular}{|c|c|c|c|}
\hline Ełapa & \multicolumn{3}{|c|}{ Descrição } \\
\hline & \multicolumn{3}{|c|}{ Seleção dos casos a partir dos indicadores e qualidades } \\
\hline 1 & $\begin{array}{l}\text { Indicadores: } \\
\text { 1. Densidade: } \\
\text { 120 a } 850 \text { hab./ha } \\
\text { 2. Área do lote: } \\
0,1 \text { a } 2,5 \text { ha } \\
\text { 3. Área do apto: } \\
50 \text { a } 120 \mathrm{~m}^{2} \\
\text { 4. Número de dorm.: } \\
2,3,4\end{array}$ & $\begin{array}{l}\text { Qualidades: } \\
\text { 1. Variedade de usos } \\
\text { 2. Boa iluminação } \\
\text { 3. Boa ventilação } \\
\text { 4. Riqueza visual } \\
\text { 5. Proximidade de espaços públicos } \\
\text { 6. Multiplicidade de caminhos } \\
\text { 7. Densidade de pessoas nas ruas } \\
\text { 8. Fachadas ativas } \\
\text { 9. Locais de estar } \\
\text { 10. Vegetação na calçada } \\
\text { 11. Trabalho e recreação próximos } \\
\text { 12. Acessibilidade e mobilidade }\end{array}$ & $\begin{array}{l}\text { 13. Variedade de usuários } \\
\text { 14. Visibilidade } \\
\text { 15. Calçadas espaçosas } \\
\text { 16. Diversidade comercial } \\
\text { 17. Variedade de tipos de edifícios } \\
\text { 18. Correlação entre espaços } \\
\text { internos e externos } \\
\text { 19. Fechamentos } \\
\text { (muros) permeáveis } \\
\text { 20. Distâncias confortáveis para } \\
\text { andar } \\
\text { 21. Fácil acesso às entradas } \\
\text { 22. Não murar as esquinas. }\end{array}$ \\
\hline
\end{tabular}

\begin{tabular}{|c|c|c|}
\hline \multirow[b]{2}{*}{2} & \multicolumn{2}{|c|}{ Caracterização e comparação dos empreendimentos segundo variáveis inerentes à planta } \\
\hline & $\begin{array}{l}\text { Variáveis: } \\
\text { 1. Volumetria } \\
\text { 2. Número de pavimentos } \\
\text { 3. Número de Blocos } \\
\text { 4. Uso misto } \\
\text { 5. Tipo de organização das unidades } \\
\text { 6. Tipo de circulação } \\
\text { 7. Tipo de planta } \\
\text { 8. Número de apartamento por pavimento } \\
\text { 9. Área do pavimento }\end{array}$ & $\begin{array}{l}\text { 10. Área de circulação por pavimento } \\
\text { 11. Área total de circulação do edifício } \\
\text { 12. Área de lazer livre } \\
\text { 13. Área de lazer coberto } \\
\text { 14. Área total construída } \\
\text { 15. Coeficiente de aproveitamento (CA) } \\
\text { 16. Taxa de ocupação (TO) } \\
\text { 17. Índice de compacidade } \\
\text { 18. Perímetro do edifício }\end{array}$ \\
\hline & \multicolumn{2}{|l|}{ Analise da legislação urbana } \\
\hline & \multicolumn{2}{|c|}{$\begin{array}{l}\text { Analise da legislação urbana dos casos segundo o gráfico spacemate proposto por Berghauser } \\
\text { Pont e Haupt (2009) de modo a verificar a viabilidade. }\end{array}$} \\
\hline
\end{tabular}

Fonte: o autor (2019)

\subsection{Aplicação da estratégia}

\subsubsection{Seleção dos casos}

Foram selecionados dois edifícios em Londrina, PR, localizados no bairro Gleba Palhano. A escolha deste local ocorreu devido à concentração recente e expressiva de edifícios com as características e impactos citados. Estes casos intitulados 116 e 152 apartamentos Londrina foram lançados por incorporadora classificada entre as maiores no Brasil em 2018 segundo a empresa ITC. Os dois casos europeus foram selecionados, a partir de publicação recente de Per, Mozas e Arpa (2007) sobre o tema que contempla as informações necessárias para o estudo. $O$ primeiro edifício foi intitulado 106 aptos, Madri, Espanha e o segundo com nome de 125 apartamentos, Paris, França. Os quatro casos foram agrupados em pares de acordo com as semelhanças dos indicadores: 116 aptos, Londrina com 106 aptos, Madri e 152 aptos, Londrina com 125 aptos, Paris. O quadro 2 apresenta esta separação e os números referentes aos indicadores. 
Quadro 2 - Casos selecionados a partir dos indicadores

\begin{tabular}{|l|c|c|c|c|}
\hline \multirow{2}{*}{ Indicadores } & \multicolumn{2}{|c|}{ Caso 1 } & \multicolumn{2}{c|}{ Caso 2 } \\
\cline { 2 - 5 } & $\begin{array}{c}\text { 116 aptos } \\
\text { Londrina }\end{array}$ & $\begin{array}{c}\text { 106 aptos } \\
\text { Madri }\end{array}$ & $\begin{array}{c}\text { 152 aptos } \\
\text { Londrina }\end{array}$ & $\begin{array}{c}\text { 125 aptos } \\
\text { Paris }\end{array}$ \\
\hline 1. Densidade Habitacional (U.H./ha) & 237 & 232 & 375 & 387 \\
\hline 2. área do lote (hectares) & 0,455 & 0,456 & 0,405 & 0,323 \\
\hline 3. Área do apartamento $\left(\mathrm{m}^{2}\right)$ & 122 & 67 a 112 & 95 & 52 a 106 \\
\hline 4. Número de dormitórios & 2,3 & $2,3,4$ & 3 & $1,2,3,4$ \\
\hline
\end{tabular}

Fonte: o autor (2019)

A partir de informações extraídas dos projetos e imagens de satélite foi possível verificar a presença ou não das recomendações de qualidade da rua intimamente relacionadas com os edifícios. O quadro 3 revela que as recomendações nos casos europeus são predominantes. 0 oposto ocorre nos casos brasileiros onde apenas algumas foram reconhecidas.

\section{Quadro 3 - Reconhecimento das recomendações de qualidade da rua nos casos}

\begin{tabular}{|c|c|c|c|c|c|c|c|c|c|}
\hline Qualidades & $\begin{array}{l}\text { 음 } \\
\text { 동 } \\
\text { 음 } \\
=0\end{array}$ & 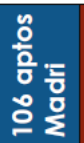 & 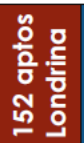 & 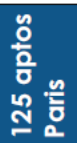 & Qualidades & 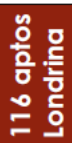 & $\begin{array}{l}\text { 응 } \\
\text { 응 등 } \\
\text { 응 }\end{array}$ & 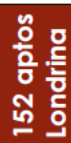 & 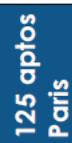 \\
\hline 1. Variedade de usos & Não & Sim & Não & Sim & 13. Variedade de usuários & Não & $\operatorname{sim}$ & Não & $\operatorname{sim}$ \\
\hline 2. Boa iluminação & Sim & Sim & Sim & Sim & 14. Boa visibilidade & Não & Sim & Não & Sim \\
\hline 3. Boa ventilação & Sim & Sim & Sim & Sim & 15. Calçadas espaçosas & Não & Sim & Não & Sim \\
\hline 4. Riqueza visual & Não & Sim & Não & Sim & 16. Diversidade comercial & Não & Sim & Não & Sim \\
\hline 5. Próximo a áreas livres & Sim & Sim & Sim & Sim & 17. Movimento pessoas & Não & Sim & Não & Sim \\
\hline 6. Múltiplos caminhos & Não & Sim & Não & Sim & 18. Variedade edifícios & Não & Sim & Não & Sim \\
\hline 7. Pessoas nas ruas & Não & Sim & Não & Sim & 19. Correlação espaços & Não & Sim & Não & Sim \\
\hline 8. Fachadas ativas & Nâo & Sim & Não & Sim & 20. Fechamento permeável & Não & Sim & Não & Sim \\
\hline 9. Locais de estar & Não & Sim & Não & Sim & 21. Distâncias confortáveis & Não & Sim & Não & Sim \\
\hline 10. Calçadas vegetação & Sim & Sim & Sim & Sim & 22. Fácil acesso & Não & Sim & Não & $\operatorname{sim}$ \\
\hline 11. Trabalho e recreação & Sim & Sim & Sim & Sim & 23. Não murar esquinas & Não & Sim & Não & Sim \\
\hline 12. Acessibilidade e mob. & Sim & Sim & Sim & Sim & & & & & \\
\hline
\end{tabular}

As semelhanças entre os indicadores e a presença predominante das recomendações de qualidade nos casos europeus reforçaram a utilização destes edifícios como casos com potencial para extrair características positivas para novos empreendimentos.

\subsubsection{Caracterização e comparação dos casos}

O quadro 4 apresenta a caracterização dos casos 1 e 2. Os indicadores são semelhantes conforme as diretrizes pré-estabelecidas. Já as variáveis apresentam diferenças. As diferenças expressivas entre os edifícios do caso 1 abrangem a maioria das variáveis exceto o número de blocos, a área de circulação total, área de lazer livre, coberto e coeficiente de aproveitamento que apresentam semelhanças. Com 
relação aos edifícios do caso 2 as diferenças também predominam entre as variáveis exceto o tipo de organização das unidades, área de circulação por pavimento, área de lazer livre, coeficiente de aproveitamento, índice de compacidade e perímetro com semelhanças. O maior número de variáveis semelhantes no caso 2 pode ser explicado em função do maior número de blocos, aproximando variáveis como: tipo de organização das unidades, área de circulação por pavimento, índice de compacidade e perímetro.

Quadro 4 - Variáveis dos edifícios

\begin{tabular}{|c|c|c|c|c|}
\hline \multirow[b]{2}{*}{ Variáveis } & \multicolumn{2}{|c|}{ Caso 1} & \multicolumn{2}{|c|}{ Caso 2} \\
\hline & $\begin{array}{l}116 \text { aptos, } \\
\text { Londrina }\end{array}$ & $\begin{array}{l}106 \text { aptos, } \\
\text { Madri }\end{array}$ & $\begin{array}{l}152 \text { aptos, } \\
\text { Londrina }\end{array}$ & $\begin{array}{l}125 \text { aptos, } \\
\text { Paris }\end{array}$ \\
\hline Volumetria & & & & \\
\hline $\mathrm{N}^{\circ}$ Pavimentos & 27 & 7 & 19 & 7 \\
\hline $\mathrm{N}^{\circ}$ blocos & 1 & 1 & 2 & 3 \\
\hline Uso misto & Não & Sim & Não & Sim \\
\hline $\begin{array}{l}\text { Tipo de org. das } \\
\text { unidades }\end{array}$ & Agrupadas & Em fita & Agrupadas & Agrupadas \\
\hline $\begin{array}{l}\text { Tipo de } \\
\text { Circulação }\end{array}$ & $\begin{array}{l}\text { Vertical } \\
\text { centralizada } \\
\text { sem corredor }\end{array}$ & $\begin{array}{l}\text { Vertical } \\
\text { descentralizada } \\
\text { sem corredor }\end{array}$ & \begin{tabular}{|l|} 
Vertical \\
centralizada \\
sem corredor
\end{tabular} & $\begin{array}{l}\text { Vertical } \\
\text { centralizada c/ } \\
\text { corredor interno }\end{array}$ \\
\hline Tipo de planta & Compacta & Em "U" & Compacta & Em "L" \\
\hline \multicolumn{5}{|l|}{ Planta do edifício } \\
\hline Apto/pav. & 4 & $4,10,14,18,20$ & 8 & $7,8,18,20$ \\
\hline Área pav. $\left(\mathrm{m}^{2}\right)$ & 568,00 & $\begin{array}{l}750,00 ; 1.400,00 \\
1.745,00 ; 1.950,00\end{array}$ & 456,$00 ; 456,00$ & $\begin{array}{l}564,00 ; 540,00 \\
673,00\end{array}$ \\
\hline Circ. /pav. $\left(\mathrm{m}^{2}\right)$ & 60,00 & 190,00 & 125,00 & 131,00 \\
\hline Circ. total $\left(\mathrm{m}^{2}\right)$ & $1.740,00$ & $1.349,00$ & $2.500,00$ & $1.114,00$ \\
\hline Lazer livre $\left(\mathrm{m}^{2}\right)$ & $2.485,00$ & $2.525,00$ & $1.296,00$ & $1.264,00$ \\
\hline Lazer cob. $\left(\mathrm{m}^{2}\right)$ & 686,00 & 956,00 & 840,00 & 170,00 \\
\hline Construção $\left(\mathrm{m}^{2}\right)$ & $15.110,00$ & $12.380,00$ & $16.145,00$ & $12.120,00$ \\
\hline CA & 3,3 & 2,7 & 4,0 & 3,7 \\
\hline TO $(\%)$ e $\left(m^{2}\right)$ & 12,5 e 568,00 & 43 e $1.950,00$ & 22,5 e 913,00 & 55 e $1.777,00$ \\
\hline IC (\%) & 61 & 38 & 56,56 & $59,61,52$ \\
\hline Perímetro (m) & 140,00 & 411,00 & 136,$00 ; 136,00$ & $\begin{array}{l}143,00 ; 135,00 ; \\
176,00\end{array}$ \\
\hline
\end{tabular}

Fonte: Per, Mozas, Arpa (2007) e incorporadora londrinense adaptado pelo autor (2019) 


\subsubsection{Análise dos casos segundo o gráfico spacemate}

Os quadros 5 e 6 revelam a posição dos edifícios estrangeiros e nacionais no gráfico. A partir dos índices urbanísticos previstos na legislação de Londrina, PR foi possível simular o potencial de aplicabilidade das plantas identificadas.

\section{Quadro 5 - Gráfico Spacemate caso 1}

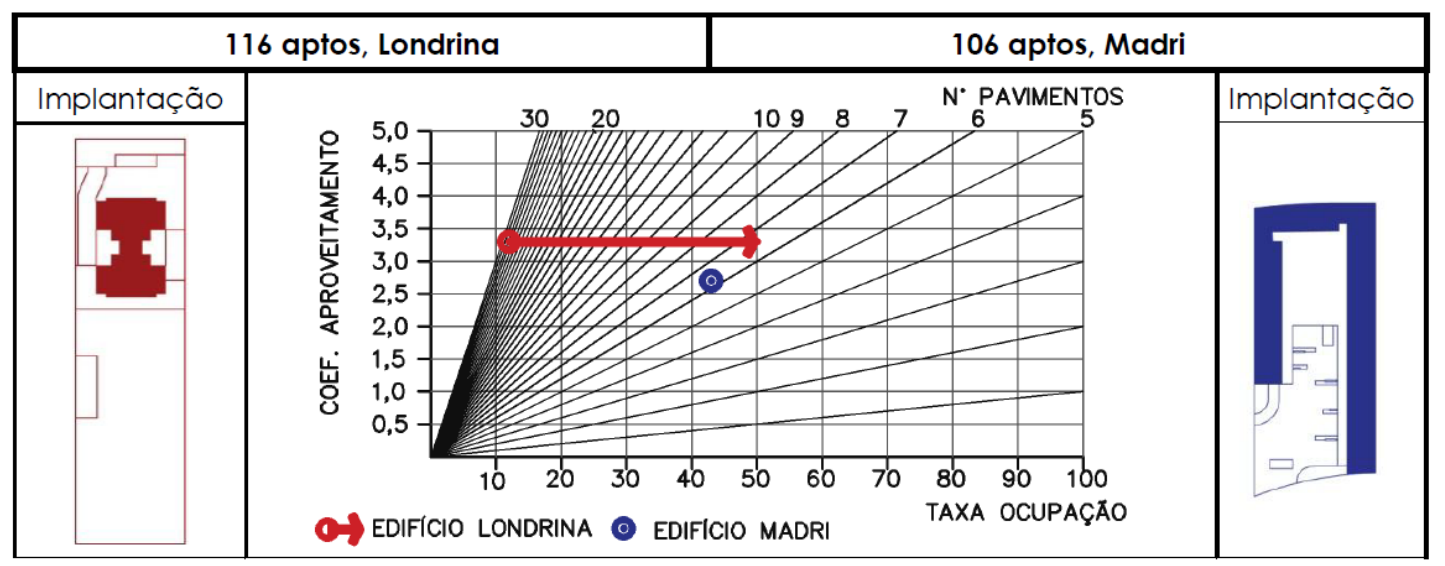

Fonte: o autor (2019)

\section{Quadro 6-Gráfico Spacemate caso 2}

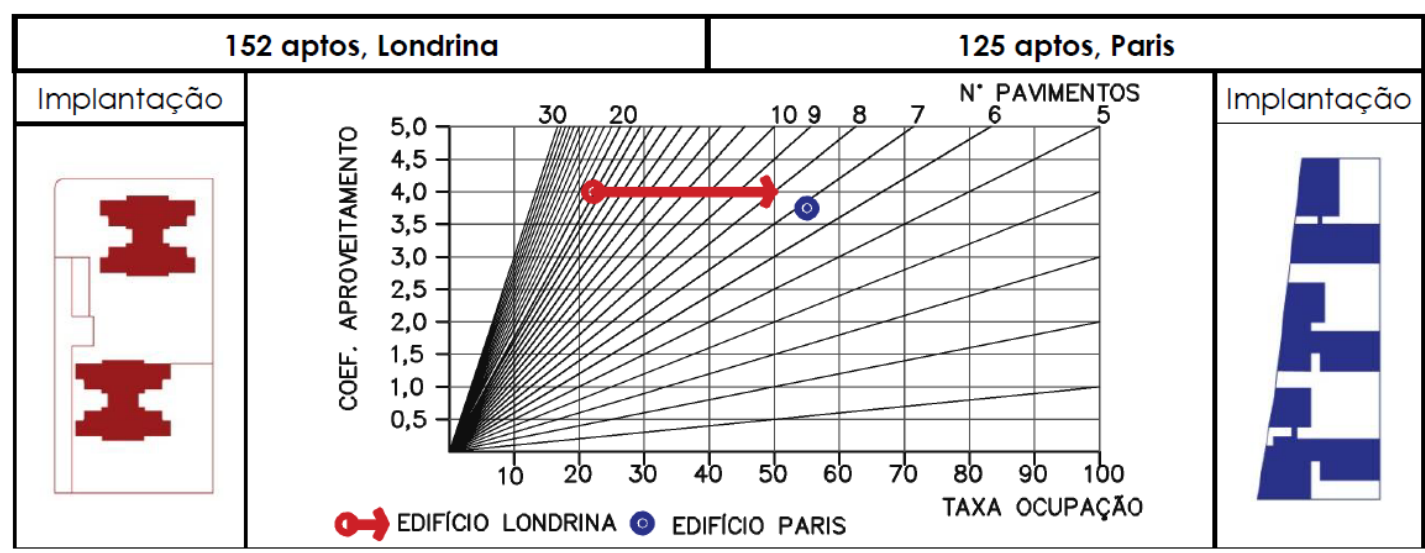

Fonte: o autor (2019)

Em ambos os casos se observa que a legislação de Londrina permite a aproximação da posição dos casos europeus, pois, a taxa de ocupação máxima é igual a 50\%. Ou seja, é possível projetar novos edifícios com plantas semelhantes aos internacionais e aumentar a qualidade tanto dos empreendimentos quanto da rua. Este incremento qualitativo pode ampliar a satisfação dos usuários e sobrepor acréscimos de investimentos decorrentes do aumento do índice de compacidade das plantas (MASCARÓ, 2003). Apesar da relevância deste assunto não será abordado neste trabalho, porém, pode oferecer valiosas contribuições se estudados em futuras pesquisas. 


\section{CONCLUSÕES}

A estratégia de análise se mostrou eficaz por promover a seleção sistemática de edifícios em diferentes contextos a partir de indicadores fundamentais e recomendações de qualidade da rua. Também viabilizou a comparação das variáveis e possibilitou a análise do potencial de aplicação dos novos desenhos segundo a legislação urbana. De forma preliminar é possível identificar que as plantas dos edifícios europeus são alternativas positivas, pois, vão ao encontro dos requisitos para o aumento da qualidade da rua e são aplicáveis segundo os índices urbanísticos, considerando o caso de Londrina, PR, mesmo com maior taxa de ocupação. Podemos citar como a principal característica dos edifícios estrangeiros a diversidade indicada por Jacobs (2000) desde a década de 1960. Destaca-se a diversidade de uso, de forma, espaços e de configuração da planta que é a base de toda experimentação. Não se trata de propor a eliminação do tipo de edifício predominante no Brasil, mas de apresentar alternativas para encorajar a diversidade, visando à melhoria da qualidade de futuros empreendimentos e bairros no Brasil.

\section{AGRADECIMENTO}

À CAPES, pelo apoio financeiro.

\section{REFERÊNCIAS}

APPLEYARD, D. Livable streets. Berkeley: University of California Press, 1981.

BENEVOLO, L. A arquitetura no novo milênio. São Paulo: Estação liberdade, 2007.

BENTLEY, I.; ALCOOK, A.; MURRAIN, P.; MCGLYNN, S.; SMITH, G. Entornos vitales. Hacia un diseño urbano y arquitectónico más humano: Manual prático. Barcelona: Gustavo Gili, 1999.

BERGHAUSER PONT, M.; HAUPT, P. Space, Density and Urban Form. Delft: Technische Universiteit Delft, 2009.

BRANDSTETTER, M. C. G. de O.; PACHECO, M. C.; CANEDO, N. R. de MELO. Subsídios para o desenvolvimento do produto no mercado imobiliário mediante indicadores de oferta. REEC. v.1, n.4, p. 42-53, ago. 2012.

BRANDÃO, D. Q. Diversidade e Potencial de Flexibilidade de Arranjos Espaciais de Apartamentos: uma análise do produto imobiliário no Brasil. 2002. 443 f. Tese (Doutorado em Engenharia Civil) - Universidade Federal de Santa Catarina, Florianópolis, 2002.

CAMARGO, G. L. Classificação tipológica de edifícios altos de apartamentos: o caso da Gleba Palhano em Londrina, PR. 2017. $160 f$. 
Dissertação (mestrado em arquitetura) - Universidade Estadual de Londrina, Londrina, 2017.

CAMPOS FILHO, C. M. Cidades brasileiras: Seu controle ou o caos. O que cidadãos devem fazer para humanização das cidades do Brasil. 4.ed. São Paulo: Studio Nobel, 2001.

CARMONA, M.; HEATH, T.; OC, T.; TIESDELL, S. Public Places Urban Spaces. The Dimension of Urban design. 2. ed. Oxford: Elsevier, 2010.

CARVALHO, J. P. A Tipologia dos Edifícios de Apartamentos e Sua Relação Com o Tecido Urbano da Cidade: um estudo de suas transformações nos últimos $\mathbf{4 0}$ anos. São Paulo, 2008. 224 f. Dissertação (Mestrado em Planejamento Urbano e Regional) - Universidade de São Paulo, São Paulo, 2008.

CALDEIRA, T. P. do R. Cidade de muros, crime, segregação e cidadania em São Paulo. São Paulo: Edusp. 2000.

CHING, F. D. K. Arquitetura: Forma, espaço e ordem. 1. ed. São Paulo: Martins Fontes, 1998.

EMBRAESP. EMBRAESP: Empresa Brasileira de Estudos de Patrimônio. 2019. Disponível em: https://embraesp.com.br/. Acesso em: 16 nov. 2018.

GEHL, J. Live Between Buildings Using Public Space. Washington: Island Press, 2011.

GIL, Antônio Carlos. Como elaborar projetos de pesquisa. 4. ed. São Paulo: Atlas, 2007.

GONZAGA, L. M. R. Contribuição para o aumento do nível de precisão das avaliações imobiliárias através da análise de preferencia do consumidor . 2013. $111 \mathrm{f}$. Dissertação (mestrado em engenharia civil) Universidade Federal do Rio Grande do Sul, Porto Alegre, 2013.

GUADANHIM, S. J. Habitação coletiva contemporânea: 1990-2010. 1. Ed. Londrina: Humberto Yamaki, 2014.

JACOBS, J. (1961). Morte e vida das grandes cidades. 1. Ed. Martins Fontes, 2000.

KANASHIRO, M. Leituras possíveis. In GUADANHIM, S. Habitação coletiva contemporânea: 1990-2010. 1. Ed. Londrina: Humberto Yamaki, 2014.

MASCARÓ, J. L. Manual de loteamentos e urbanização. 2 ed. Porto Alegre: Sagra Luzzatto, 1989.

MAUÁ, L. B.C. Qualidade do espaço público-Rua-em áreas de ocupação vertical recente: discussão baseada em estudo de caso. 2015. 124f. Dissertação (mestrado em arquitetura) - Universidade Estadual de Londrina, Londrina, 2015. 
ORSTEIN, S. W.; VILLA, S. B.; ONO, R. Residential high-rise buildings in São Paulo: aspects related to the adequacy to the occupant's needs. J Hous and the Built Environ, (online), v.26. p. 73-84, 2010.

PER, A. F.; MOZAS, Javier; ARPA, Javier. A visual analysis of 64 collective housing projects. Espanha: Vitoria-Gasteiz a+† Ediciones, 2007.

PINHO, Â. Conexão: apartamentos e mídias em Belo Horizonte. São Carlos, 2005. 130f. Dissertação (Mestrado em Arquitetura) - Escola de Engenharia de São Carlos, Universidade de São Paulo, São Carlos, 2005.

QUEIROZ, F. A. de; TRAMONTANO, M. Uma visão sistêmica do processo de design de edifícios de apartamentos. In: V!RUS. n.3. São Carlos: Nomads.usp, 2010.

RAPOPORT, A. L importância y la natureza de la percepción ambiental. In: Aspectos humanos de la forma urbana. Hacia una confrontación de las ciencias sociales com el diseño de la forma urbana. Barcelona: Gustavo Gili, 1978.

ROCCO, L. F. Qualidade Negociada. [Entrevista concedida a] Haifa Y. Sabbag. Revista AU, São Paulo, n.145, p. 64-46. abr. 2006.

RODRIGUES, M. A. A.; HEINECK, L. F. M. A construtibilidade no processo de projeto de edificações. VII workshop brasileiro: Gestão do processo de projeto na construção de edifícios. 2007. P.1-5.

SILVA, B. T. L.; SILVA, C. M. da S.; ARAUJO, F. F. de. Comportamento do consumidor no mercado imobiliário: Atributos relevantes na

compra de imóveis no Rio de Janeiro. Sociedade, Contabilidade e Gestão. Rio de Janeiro, v. 8, n. 2, p. 6-27, mai./ago. 2013.

SILVEIRA, F. de A.; SILVEIRA, J. A. R. da. Qualidade do espaço residencial: efeitos da verticalização no bairro de Tambaú, na cidade de João Pessoa (PB). Urbe Revista Brasileira de Gestão Urbana. Curitiba. v.6, n.3, p. 289-305, set./dez. 2014.

TEIXEIRA, Cristiano André; INVIDIATA, Andréa; SORGATO, Marcio José; MELO, Ana Paula; FOSSATI, Michele; LAMBERTS, Roberto. Centro Brasileiro de Eficiência Energética em edificações: Levantamento das características de edifícios residenciais brasileiros. Santa Catarina: UFSC, 2015.

VIVIAN, M.; SABOYA, R. T. de. Arquitetura, espaço urbano e criminalidade: relações entre espaço construído e segurança com foco na visibilidade. In: ENANPARQ Encontro da Associação Nacional de Pesquisa e Pós-graduação em Arquitetura e Urbanismo, II.; 2012, Natal. Anais [...]. Natal: UFRN, 2016. p. 1-20. 
VILLA, S. B.; SARAMAGO, R. de C. P.; CARDOSO, C. C. M.; PAULINO, M. J. de A. Habitar vertical: avaliação da qualidade espacial e ambiental de edifícios de apartamentos. Ambiente Construído, Porto Alegre, v. 18, n. 1, p. 519-538, jan./mar. 2018.

VILLA, S. B. Morar em apartamentos: a produção dos espaços privados e semi-privados nos edifícios ofertados pelo mercado imobiliário no século XXI em São Paulo e seus impactos na cidade de Ribeirão Preto. Critérios para avaliação pós-ocupação. 2008. 358f. Tese (Doutorado em Arquitetura) - Universidade de São Paulo, São Paulo, 2008.

WHITE, W. The social life of small urban space. Washington: The Consevation Fundation, 1980.

YIN, ROBERT K. Estudo de caso: planejamento e métodos. 3.ed. Porto Alegre: Bookman, 2013. 